\title{
Antimicrobial Susceptibility Pattern of Corynebacterium striatum
}

\author{
LUIS MARTÍNEZ-MARTÍNEZ, ${ }^{1,2 *}$ ALVARO PASCUAL, ${ }^{1,2}$ KATHRYN BERNARD, ${ }^{3}$ \\ AND ANA ISABEL SUÁREZ ${ }^{1}$ \\ Department of Microbiology, Hospital Universitario Virgen Macarena ${ }^{1}$ and Department of Microbiology, \\ School of Medicine, ${ }^{2}$ Seville, Spain, and Laboratory for Bacteriology and Enteric Pathogens, \\ Laboratory Centre for Diseases Control, Ottawa, Canada ${ }^{3}$
}

Received 26 February 1996/Returned for modification 11 June 1996/Accepted 12 September 1996

\begin{abstract}
The in vitro activities of 16 antimicrobial agents against 86 strains of Corynebacterium striatum were evaluated by microdilution using cation-adjusted Mueller-Hinton broth. MICs at which $90 \%$ of strains were inhibited were $0.06 \mu \mathrm{g} / \mathrm{ml}$ for teicoplanin, $1 \mu \mathrm{g} / \mathrm{ml}$ for vancomycin, 0.03 to $8 \mu \mathrm{g} / \mathrm{ml}$ for $\beta$-lactams, $8 \mu \mathrm{g} / \mathrm{ml}$ for sparfloxacin, $16 \mu \mathrm{g} / \mathrm{ml}$ for ciprofloxacin, $16 / 304 \mu \mathrm{g} / \mathrm{ml}$ for co-trimoxazole (trimethoprim-sulfamethoxazole), 64 $\mu \mathrm{g} / \mathrm{ml}$ for tetracycline, $128 \mu \mathrm{g} / \mathrm{ml}$ for gentamicin, and $>128 \mu \mathrm{g} / \mathrm{ml}$ for amikacin, erythromycin, and rifampin.
\end{abstract}

Information on the susceptibility of coryneform bacteria to antimicrobial agents is scarce (1). Most of the reports have referred to Corynebacterium jeikeium or C. urealyticum (2, 3, 11, 13). The activity of particular antimicrobial groups, i.e., fluoroquinolones (5), and studies comparing different methodologies (4) have also been reported. Soriano et al. recently reported the activity of 18 antimicrobial agents against 265 strains of Corynebacterium spp. and other non-spore-forming gram-positive rods, but for some species, including C. striatum, a limited number of strains was evaluated (14).

While studying the etiological role of coryneform bacteria in human infections, our group has recognized $C$. striatum as an important cause of both colonization and infection in humans (8). In a previous report (7), data on the susceptibility testing of 31 strains of $C$. striatum by disk diffusion were presented. The aim of this study is to extend these preliminary data by determining MICs of 16 antimicrobial agents against 86 strains of $C$. striatum isolated from clinical samples.

(This work was presented at the 35th Interscience Conference on Antimicrobial Agents and Chemotherapy, San Francisco, Calif., 17 to 20 September 1995 [6].)

Eighty-six strains of $C$. striatum isolated in the period between January 1991 to October 1994 from clinical samples of different patients at the University Hospital V. Macarena, Seville, Spain, were studied.

Fifty-nine strains were isolated from wound exudates, seven from catheter tips, seven from bronchial aspirates, three from urine, two from blood cultures, two from abscesses, and six from other origins. The first 24 organisms were identified with all conventional tests, the API CORYNE system, and cellular fatty acids profiles, as previously described (7). The remaining 62 strains were identified with the API CORYNE system. Hydrolysis of tyrosine, morphology of the organism in gram stain, and colonial morphology were additionally assessed to confirm the identification of these 62 strains (7).

After identification, bacteria were maintained in $10 \%$ glycerol in tryptic soy broth at $-70^{\circ} \mathrm{C}$ until they were used. Staphylococcus aureus ATCC 29213 and Enterococcus faecalis ATCC 29212 were used as control strains.

An in-house microdilution method was used in accordance with the NCCLS guidelines (9). Although Mueller-Hinton

\footnotetext{
* Corresponding author. Mailing address: Department of Microbiology, School of Medicine, Apdo 914, 41080 Seville, Spain. Phone: 34.5.4557448. Fax: 34.5.4377413.
}

broth containing $0.5 \%$ Tween 80 has been previously used in our laboratory $(4,5)$ for susceptibility studies of coryneform bacteria, cation-adjusted Mueller-Hinton broth (CaMHB) was used in this study, since in preliminary experiments we observed that it allows for sufficient growth of $C$. striatum (data not shown). The following antimicrobial agents were used as powders of known potency: penicillin G (Sigma, St. Louis, Mo.), ampicillin (Smith-Kline Beecham, Madrid, Spain), cefazolin (Sigma), cefuroxime (Sigma), cefotaxime (Hoechst, Barcelona, Spain), imipenem (Merck Sharp \& Dohme, Madrid, Spain), gentamicin (Sigma), amikacin (Bristol Myers-Squibb, Madrid, Spain), erythromycin (Sigma), co-trimoxazole (Galloso, Madrid, Spain), tetracycline (Sigma), rifampin (Sigma), vancomycin (Lilly SA, Madrid, Spain), teicoplanin (Merrell Dow España, Madrid, Spain), ciprofloxacin (Bayer AG, Barcelona, Spain), and sparfloxacin (Rhône Poulenc Europe, Antony, France). A range of 0.06 to $128 \mu \mathrm{g} / \mathrm{ml}$ for penicillin, ampicillin, cefazolin, cefuroxime, cefotaxime, gentamicin, amikacin, erythromycin, tetracycline, and rifampin, 0.015 to 16 $\mu \mathrm{g} / \mathrm{ml}$ for imipenem, vancomycin, teicoplanin, ciprofloxacin, and sparfloxacin, and 0.015 and 0.297 (trimethoprim-sulfamethoxazole) to 16 and $304 \mu \mathrm{g} / \mathrm{ml}$ for co-trimoxazole were tested. Bacteria from cultures grown on Columbia agar with 5\% sheep blood for 20 to $24 \mathrm{~h}$ were suspended in CaMHB to a concentration of $10^{8} \mathrm{CFU} / \mathrm{ml}$. This suspension was diluted to obtain $5 \times 10^{4} \mathrm{CFU}$ per well. The final volume in each well of the microtiter plate was $100 \mu$ l. Once inoculated, plates were incubated at $35^{\circ} \mathrm{C}$ for $18 \mathrm{~h}$. The MIC was determined to be the lowest concentration of antimicrobial agent that inhibited visible growth.

Most of the studies on susceptibility testing of coryneform bacteria describe antibiograms of the fastidious species $C$. jeikeium or $C$. urealytium, both of which frequently require an enriched medium (i.e., one containing blood or Tween 80) to grow. In this study, we observed that the nonfastidious species C. striatum grows well in CaMHB after overnight incubation. In our opinion, this medium should be considered for susceptibility testing of all nonfastidious coryneform bacteria. The MIC (range and MICs for 50\% [ $\left.\mathrm{MIC}_{50}\right]$ and for 90\% [ $\left.\mathrm{MIC}_{90}\right]$ of isolates tested) of the different antimicrobial agents evaluated are presented in Table 1.

$\mathrm{MIC}_{90} \mathrm{~s}$ were $\leq 1 \mu \mathrm{g} / \mathrm{ml}$ for penicillin, cefazolin, imipenem, vancomycin, and teicoplanin.

$\mathrm{MIC}_{90} \mathrm{~s}$ of teicoplanin were two to four dilution steps lower than those of vancomycin. García-Rodríguez et al. also showed a lower $\mathrm{MIC}_{90}$ of teicoplanin than that of vancomycin against 
TABLE 1 . In vitro activity of 16 antimicrobial agents against 86 C. striatum strains isolated from clinical samples

\begin{tabular}{lccc}
\hline $\begin{array}{c}\text { Antimicrobial } \\
\text { agent }\end{array}$ & $\begin{array}{c}\text { MIC range } \\
(\mu \mathrm{g} / \mathrm{ml})\end{array}$ & $\begin{array}{c}\mathrm{MIC}_{50} \\
(\mu \mathrm{g} / \mathrm{ml})\end{array}$ & $\begin{array}{c}\mathrm{MIC}_{90} \\
(\mu \mathrm{g} / \mathrm{ml})\end{array}$ \\
\hline Penicillin & $\leq 0.06-2$ & 0.25 & 0.5 \\
Ampicillin & $<0.06-8$ & 1 & 2 \\
Cefazolin & $\leq 0.06-8$ & 0.5 & 1 \\
Cefuroxime & $\leq 0.06-16$ & 1 & 2 \\
Cefotaxime & $\leq 0.06-32$ & 2 & 8 \\
Imipenem & $\leq 0.015-4$ & 0.015 & 0.03 \\
Gentamicin & $\leq 0.06-128$ & 1 & 128 \\
Amikacin & $\leq 0.015->128$ & 0.125 & $>128$ \\
Erythromycin & $\leq 0.06->128$ & 4 & $>128$ \\
Tetracycline & $\leq 0.06-64$ & 16 & 64 \\
Co-trimoxazole & $\leq 0.015->16$ & 16 & 16 \\
Rifampin & $\leq 0.06->128$ & $>128$ & $>128$ \\
Vancomycin & $0.125-2$ & 0.25 & 1 \\
Teicoplanin & $0.06-4$ & 0.06 & 0.06 \\
Ciprofloxacin & $\leq 0.015->16$ & 4 & 16 \\
Sparfloxacin & $\leq 0.008->16$ & 2 & 8 \\
\hline
\end{tabular}

C. urealyticum (2), although other authors have observed similar values for both antimicrobial agents against $C$. urealyticum and $C$. jeikeium (11). $\mathrm{MIC}_{90}$ s of $\beta$-lactams ranged from 0.03 $\mu \mathrm{g} / \mathrm{ml}$ (imipenem) to $8 \mu \mathrm{g} / \mathrm{ml}$ (cefotaxime). None of the strains produced $\beta$-lactamase, as determined by the nitrocefin test (10). These results confirm the in vitro activity of $\beta$-lactams against $C$. striatum, as has been previously described using the disk diffusion assay (6). Amikacin was $\geq 4$ times more active than gentamicin against $51 \%$ of the strains. Gentamicin was $\geq 4$ times more active than amikacin against $7 \%$ of the strains. Both aminoglycosides had low activity (MIC $>128 \mu \mathrm{g} / \mathrm{ml}$ ) against $30 \%$ of the strains. Sparfloxacin was more active than ciprofloxacin against $C$. striatum, yielding MICs one or more dilution steps lower against $51 \%$ of the strains. We have previously reported that new fluoroquinolones are more active than ciprofloxacin and sparfloxacin against $C$. striatum: clinafloxacin had an $\mathrm{MIC}_{50}$ of 0.125 and an $\mathrm{MIC}_{90}$ of $1 \mu \mathrm{g} / \mathrm{ml}(5)$. Co-trimoxazole, tetracycline, erythromycin, and rifampin had poor activity against $C$. striatum; less than $50 \%$ of the strains were inhibited by $16 / 304 \mu \mathrm{g} / \mathrm{ml}$ (trimethoprim-sulfamethoxazole), 16,4 , and $>128 \mu \mathrm{g} / \mathrm{ml}$, respectively, of these agents.

To the best of our knowledge, there is only one study (14) in which the susceptibility of $C$. striatum to several antimicrobial agents was quantitatively determined using a representative number of strains (11 isolates). There is a good overall agreement between this study and ours, but differences have been observed for rifampin, ciprofloxacin, and gentamicin. The $\mathrm{MIC}_{50}$ of rifampin and ciprofloxacin are higher in our study $(>128$ and $4 \mu \mathrm{g} / \mathrm{ml}$ ) than in the study by Soriano et al. ( 2 and $0.25 \mu \mathrm{g} / \mathrm{ml}$ ) (15). Similarly, the $\mathrm{MIC}_{90}$ of gentamicin was also higher in our study $(128 \mu \mathrm{g} / \mathrm{ml}$ versus $2 \mu \mathrm{g} / \mathrm{ml})$. The larger number of strains in our study could be related to a higher probability of finding different antibiotypes of $C$. striatum, but it is difficult to determine the basis (i.e., temporal, geographical, etc.) accounting for these differences.

There are not breakpoints from the NCCLS to assign interpretative categories for coryneform bacteria. Considering MICs of the antimicrobial agents evaluated against $C$. striatum above the intermediate breakpoint for staphylococci as a reference of decreased in vitro antimicrobial activity, we have observed little simultaneous activity of several agents against some C. striatum strains. The most common phenotypes included decreased susceptibility to erythromycin, tetracycline, cotrimoxazole, fluoroquinolones, and rifampin (38\% of strains); to erythromycin, tetracycline, cotrimoxazole, fluoroquinolones, and aminoglycosides (14\% of the strains); and to erythromycin, tetracycline, cotrimoxazole, fluoroquinolones, and rifampin ( $8 \%$ of the strains).

The molecular basis of the mechanisms of resistance to antimicrobial agents in $C$. striatum is poorly known. Roberts et al. (12) reported that 15 of 17 strains carried the ermCd gene and were resistant or intermediately resistant to erythromycin; 13 strains also carried the tet $M$ gene and were tetracycline resistant. New studies are needed in order to obtain information about the mechanisms of resistance of $C$. striatum to other antimicrobial agents commonly used in clinics, including fluoroquinolones, aminoglycosides, co-trimoxazole, and rifampin.

As the clinical relevance of $C$. striatum is increasingly recognized $(7,8,15)$, the data obtained in this study may support therapeutic options against the infections caused by this organism, which could allow the establishment of breakpoints for the assignment of in vitro activity data to interpretative clinical categories.

We gratefully acknowledge the help of Judith Winstanley for her contribution in the identification of $C$. striatum and of Patricia Hidalgo and Janet Dawson for manuscript preparation.

\section{REFERENCES}

1. Coyle, M. B., and B. A. Lipsky. 1990. Coryneform bacteria in infectious diseases: clinical and laboratory aspects. Clin. Microbiol. Rev. 3:227-246.

2. García-Rodríguez, J. A., J. E. García Sánchez, J. L. Muñoz Bellido, T. Nebreda Mayoral, E. García Sánchez, and I. García García. 1991. In vitro activity of 19 antimicrobial agents against Corynebacterium group D2. Antimicrob. Agents Chemother. 35:2140-2143.

3. Machka, K., and H. Balg. 1984. In vitro activity of ciprofloxacin agains group JK corynebacteria. Eur. J. Clin. Microbiol. 3:375.

4. Martínez-Martínez, L., M. C. Ortega, and A. I. Suárez. 1995. Comparison of E-test with broth microdilution and disk-diffusion for susceptibility testing of coryneform bacteria. J. Clin. Microbiol. 33:1318-1321.

5. Martínez-Martínez, L., A. I. Suárez, M. C. Ortega, and E. J. Perea. 1994 Comparative in vitro activities of new quinolones against coryneform bacteria. Antimicrob. Agents Chemother. 38:1439-1441.

6. Martínez-Martínez, L., A. Pascual, K. Bernard, and A. I. Suárez. 1995 Antimicrobial susceptibility pattern of Corynebacterium striatum, abstr. E93, p. 102. In Program and abstracts of the 35th Interscience Conference on Antimicrobial Agents and Chemotherapy. American Society for Microbiology, Washington, D.C.

7. Martínez-Martínez, L., A. I. Suárez, J. Winstanley, M. C. Ortega, and K. Bernard. 1995. Phenotypic characteristics of 31 strains of Corynebacterium striatum isolated from clinical samples. J. Clin. Microbiol. 33:2458-2461.

8. Martínez-Martínez, L., et al. Submitted for publication.

9. National Committee for Clinical Laboratory Standards. 1993. Methods for dilution antimicrobial susceptibility tests for bacteria that grow aerobically, third edition. Approved standard. M7-A3. National Committee for Clinical Laboratory Standards, Villanova, Pa.

10. O'Callaghan, C. H., A. Morris, S. M. Kirby, and A. H. Shingler. 1972. Novel method for detection of $\beta$-lactamase by using a chromogenic cephalosporin substrate. Antimicrob. Agents Chemother. 1:283-288.

11. Philippon, P., and E. Bimet. 1990. In vitro susceptibility of Corynebacterium group D2 and Corynebacterium jeikeium to twelve antibiotics. Eur. J. Clin. Microbiol. Infect. Dis. 9:892-895.

12. Roberts, M. C., R. B. Leonard, R. B. Briselden, F. D. Schoenknecht, and M. B. Coyle. 1992. Characterization of antibiotic resistant Corynebacterium striatum strains. J. Antimicrob Chemother. 30:463-474.

13. Soriano, F., C. Ponte, M. Santamaría, A. Torres, and R. Fernández-Roblas. 1987. Susceptibility of urinary isolates of Corynebacterium group D2 to fifteen antimicrobials and acetohydroxamic acid. J. Antimicrob. Chemother. 20:349-355

14. Soriano, F., J. Zapardiel, and E. Nieto. 1995. Antimicrobial susceptibilities of Corynebacterium species and other non-spore-forming gram-positive bacilli to 18 antimicrobial agents. Antimicrob. Agents Chemother. 39:208-214.

15. Watkins, D. A., A. Chahine, R. J. Creger, M. R. Jacobs, and H. M. Lazarus. 1993. Corynebacterium striatum: a diphtheroid with pathogenic potential. Clin. Infect. Dis. 17:21-25. 